\title{
Group Cohesiveness and Organizational Commitment: Moderated by Transformational Leadership
}

\author{
Tzu Ying Lee \\ Feng Chia University \\ E-mail address Ltyjoyce@ms56.hinet.net
}

\begin{abstract}
This study investigated to what extent group cohesiveness is related to organizational commitment and transformational leadership. In the advent of generational transformation, it is impossible to achieve organizational goals and create win-win partnerships between supervisors and subordinates merely by resorting to organizational discipline or role behavior. This study, based on a quality interview survey, explored the influence of team cohesiveness on organizational commitment with transformational leadership as a moderating variable. Literature related to the real estate agency industry was firstly reviewed and compiled for overall understanding. In-depth onsite expert interviews were conducted for inducing internal and external affecting factors. Actual cases were analyzed. The influence of team behavior and group cohesiveness on organizational commitment was verified. It was found. Additionally, supervisors' positive transformational leadership and supportive behavior could lead to positive organizational cohesiveness. This is regarded as one of the key success factors of management. Transformational leadership behaviors that can boost positive group cohesiveness should be encouraged. Such behaviors can not only boost group cohesiveness but also enable the team to achieve the team goal efficiently.
\end{abstract}

Keywords: Group cohesiveness; Organizational commitment; Transformational leadership.

\section{INTRODUCTION}

This is an open access article under the CC-BY-NC license.

The service industry has, over the past few years, exerted increasing influence on the economy of Taiwan. Service industry management has become a focal research area in business. As a government-chartered industry, the estate agency industry requires that all professionals be supervised and disciplined by the government. Faced with challenges from the structural change of this industry, those engaged in the estate agency business need to constantly acquire more updated information and knowledge to make their organizations more resourceful. No doubt, professionals (or talents) constitute the largest asset of the estate agency business. Successful talent retention consists of using effective strategies for manpower management. Employees who are attentive to their job, energetic, enthusiastic about service, and cohesive toward their team are more likely to be loyal and committed to their organization, and therefore enhance the organizational foundation for managerial sustainment. Improper employee recruitment will lead to more organizational burden and cost. 


\section{Research Background}

In the past few years, the service industry has had an increasing impact on Taiwan's economy, and service industry management has become a key research area in the business field. As an industry authorized by the government, the real estate agency industry requires all professionals to be subject to government supervision and disciplinary action. Faced with the challenges brought about by structural changes in the industry, people engaged in the real estate brokerage business need to continuously obtain more updated information and knowledge to make their organizations more flexible.

\section{Research purposes}

There is no doubt that professionals are the greatest asset in real estate agencies, but successful talent retention lies in how to use effective human management strategies. Make it focus on work and enthusiastic service and be more loyal to their organization for employees who have a team cohesion rate. However, the current situation is that the organization's talent retention and insufficient team cohesion have led to a high turnover rate of personnel in this industry. The commitment to the organization is not high.

In view of this, this study will discuss this-Group Cohesiveness and Organizational Commitment: Moderated by Transformational Leadership.

Expect to be able to find out the key factors to achieve the goal of organizing team cohesion.

\section{LITERATURE REVIEW}

(1).

Group cohesiveness

Group cohesiveness can be defined as the extent to which team members stick together and remain united in the pursuit of a common goal. Cohesion and motivation of team members are key factors that contribute to a company's performance. There are two types of group cohesion: task cohesion, which refers to how well a team works together in order to achieve shared goals, and social cohesion, which reflects how well the members of a team get along and enjoy each other's company (Brawley, Carron, \& Widmeyer, 1987; Chang \& Bordia, 2001).

In the context of high team cohesion, members' positive connection and emotional commitment to each other will be stronger (DeLamater \& Myers, 2010), which will enhance the positive impact of psychological similarity on team trust. Conversely, in the context of low team cohesion, the positive relationship between psychological similarity and team trust will be weakened.

Table 1: Definitions of cohesion

\begin{tabular}{|c|c|l|}
\hline researchers & year & \multicolumn{1}{|c|}{ definition of group cohesiveness } \\
\hline $\begin{array}{c}\text { Festinger, Schachter \& } \\
\text { Back }\end{array}$ & 1950 & $\begin{array}{l}\text { A group-inclining power; a power preventing members } \\
\text { from leaving the team }\end{array}$ \\
\hline Festinger & 1950 & $\begin{array}{l}\text { A consolidating power which keeps members staying in the } \\
\text { team proactively }\end{array}$ \\
\hline Lewin & 1951 & $\begin{array}{l}\text { Team attractiveness including resisting leaving the team; } \\
\text { team members attack unreasonable enthusiasm; the result } \\
\text { of organization compromise }\end{array}$ \\
\hline Cartwright \& Zander & 1953 & $\begin{array}{l}\text { Team attractiveness including resisting leaving the team; } \\
\text { team members attack unreasonable enthusiasm; the result } \\
\text { of organization compromise }\end{array}$ \\
\hline Carron & 1982 & $\begin{array}{l}\text { A dynamic process where team members are closely united } \\
\text { in search of organizational goals and mission. }\end{array}$ \\
\hline \hline
\end{tabular}




\begin{tabular}{|l|r|l|}
\hline Forsyth & 1983 & $\begin{array}{l}\text { Strong identification with group relationships; collective } \\
\text { belief in group goal and value and willingness to help the } \\
\text { group }\end{array}$ \\
\hline c/George \& Bettenhausen & 1990 & $\begin{array}{l}\text { Boost team members' positive attitude toward the team by } \\
\text { developing friendship, common interest, and cooperation }\end{array}$ \\
\hline Mullen \& Copper & 1994 & $\begin{array}{l}\text { Being attracted to the team, committed to working, and } \\
\text { respect team honor }\end{array}$ \\
\hline
\end{tabular}

Sources: $\mathrm{Wu}(2002)$

\section{Hypothesis 1: Group cohesiveness has a positive influence on organizational commitment.}

\section{(2). Organizational commitment}

As an important concept in modern organizational behavior, organizational commitment has drawn heated attention from organizational behaviorists, psychologists, and those engaged in human resource management. There are two basic concepts underlying organizational commitment. The attitude approach regards organizational commitment as a process through which team members consider their relations with the organization. The other concept emphasizes whether members' value and goal are congruent with those of the team. According to Wiener (1982), employees' commitment to an organization consists of belief and a sense of responsibility. Allen \& Meyer (1990), based on comprehensive research, proposed three types of organizational commitment, including affective commitment, continuance commitment, and normative commitment. Affective commitment is meant that members identify themselves with organizational goals and value and are willing to stay in the organization and work hard for it. Continuance commitment refers to employee's cognition that leaving the organization would deprive them of value and benefit. Normative commitment means employees and organizations have value congruency or an employee's value attitude toward the organization.

\section{(3). Transformational leadership}

Downton (1973) first introduced the concept of transformational leadership. According to transformational leadership, the influence of supervisors on employees is based on different levels of transaction or employ commitment (Lin, 2002). Transformational leadership, which is rooted in influencing team members, aims to change its employees' attitude and concept. By defining the organizational mission or goal commitment, it gives team member autonomy to accomplish the goal (Yuk, 1994). Bass (1985) mentioned transformational leadership refers to team members' trust in and loyalty to leaders. Such an attitude can trigger employees' potential and confidence and therefore boost their organizational commitment and spend extra effort on their team.

Table 2: Definitions of transformational leadership

\begin{tabular}{|l|c|l|}
\hline researcher & year & \multicolumn{1}{|c|}{ Definition of transformational leadership } \\
\hline Bass & 1985 & $\begin{array}{l}\text { Members' trust in and loyalty to leaders, who boost } \\
\text { member's potential and confidence so that members are } \\
\text { committed to the team and willing to contribute more } \\
\text { efforts }\end{array}$ \\
\hline Bryman & 1992 & $\begin{array}{l}\text { Five key points including vision, vision communication, } \\
\text { granting autonomy, organizational culture, and trust }\end{array}$ \\
\hline Bass \& Avolio & 1994 & $\begin{array}{l}\text { Leadership which stresses promoting subordinate's higher- } \\
\text { level inner motivation, including charismatic influence, } \\
\text { inspiring motivation, intelligent motivation, and } \\
\text { individualized concern }\end{array}$ \\
\hline
\end{tabular}




\begin{tabular}{|l|l|l|}
\hline Hung Mingzho & 1997 & $\begin{array}{l}\text { Instead of using process, reward, control, transformational } \\
\text { leaders trigger organizational transformation by setting up } \\
\text { intangible values such as vision and shared value. They } \\
\text { reconstruct the organization's structure, mission, and } \\
\text { resource relocation, leading to organization regeneration. }\end{array}$ \\
\hline Chang Nenfa & 2007 & $\begin{array}{l}\text { Transformational leadership is rooted in respect for } \\
\text { humanity. In a democratic society, leaders should use their } \\
\text { charisma and convincing ability to win subordinates' } \\
\text { identification. They should inspire their subordinates to a } \\
\text { higher level of need. } \\
\text { They should provide vision, stimulate morale, enlighten } \\
\text { wisdom. Effective leadership lies in developing an } \\
\text { aggressive attitude and potential. }\end{array}$ \\
\hline
\end{tabular}

Hypothesis 2: Transformational leadership positively moderates the influence of group cohesiveness on organizational commitment.

\section{RESEARCH METHODOLOGY}

\section{Research subjects}

Research subjects included two estate agent supervisors and four estate agent frontline employees. All of the six interviewees were college-educated with more than five years of work experience. All interviewees, who had remained in the same position, had been supervised by more than two higher-level personnel. The interviewees had had interaction with their supervisors for more than half a year.

\section{Research method}

Qualitative research was employed for this study. Field interviews were conducted to obtain in-depth, first-hand data. The same interview protocol and interview questions were administered to each interviewee.

\section{Research steps}

(1). Deciding interview topics

The scale developed by Chang \& Bordia (2001) was employed to understand the team's overall feeling of the task and social cohesion. Interview questions include, for example, "all team members are responsible for any mistake committed" and "all team members remain united at non-office hours."

The organizational commitment scale developed by Lu et al. (2003) and the factor load measurement scale proposed by Stefens (2001) were referred to.

This study also referred to the transformational leadership scale developed by Cho (2003), which was based on the multifactor leadership questionnaire designed by Avolio (1990) (in Wu \& Lin (1998)).

(2) All interviewees had been engaged in the estate agency business for more than five years. Two of them were supervisors, and the other four were subordinates. The interviews were conducted during non-office hours. During the onsite interview, they were told about the purpose and significance of the research. They were acknowledged that research data, which served purely for 
academic research, would be kept confidential. The field interview was conducted with consensus from each interviewee.

(3) Formal interview

The onsite interview was conducted in accordance with the designed protocol. The interviewee's verbal responses were recorded for analysis.

\section{FINDING AND DISCUSSION}

The interviewed supervisors, who had been frontline sales representatives, were very conscious of subordinates' feeling. The change of organizational leadership can reflect the creation of organizational culture. In order to develop business sustainment, business leaders are supposed to change the strategy of human resource management. This study aimed to analyze and compare the contents of group cohesiveness. Qualitative research was adopted to induce and integrate collected data. Data analysis indicated that there should be no biased leadership behavior in a group. Leaders should keep core values in their minds. In their work scenario, they should flexibly apply the method and strategy addressed by transformational leadership. This study suggested that leadership behavior needs to be "man-first"-oriented. Implied in transformational leadership are two concepts, including "all-embracing" and "mutual assistance." The group can, therefore, become a harmonious team, being perfect.

\section{CONCLUSION AND FURTHER RESEARCH}

The purpose of this study was to investigate the influence of group cohesiveness on organizational commitment on the one hand, and the role supervisor's transformational leadership plays in conceptual relations. The conclusion was obtained based on data analysis:

(1). Group cohesiveness is positively correlated to organizational commitment. Business sustainment can be ensured through linking business human resources management with organizational commitment and organizational culture.

(2) Transformational leadership positively moderates the influence of group cohesiveness on organizational commitment. It enables business owners, leaders, managers, and subordinates to have a better understanding of in-group cooperation mode.

Additionally, leaders motivate in-group morale, search for progress, and face challenges. Subordinates working in an energetic and cohesive team are sure to intensely identify themselves with the organization. Employing transformational leadership can boost team cohesion and employee enthusiasm and loyalty. It can furthermore promote core ability, create organization value, and enable the team to achieve a team goal.

\section{REFERENCES}

Fan, Hsueh-Liang \& Luo Lu. (2017/02). The influence of group characteristics and social traits on group creation: the roles of group trust and group cohesiveness. 57-89, 1, Vol. 10. Journal of Organization and Management.

Hsu, Nanhsiung. (2007/07). A study of ability-orientation and intention-orientation in the management of human resources. Pp.69-83. Journal of Business, Vanung University.

Huang, Kuolong, \& Chitung Tsai (1998/12). The influence of job value and leadership behavior on employee performance. Pp. 51-85, 1, Vol 9.NTU Management Review

Jiang, Dingyu. \& Zen Boxing. (, 2003). A reflection and anticipation of team loyalty, team commitment, and organizational civil behavior. Pp. 175-209. Journal of Psychological Studies.

Li, Qingfang. (, 2013). The experiential narration of qualitative research: six lessons of a qualitative study. Gaulih Book, New Taipei City. 
Lin, Cemin. (2013/12). A Study of the influence of soccer coach's leadership behavior, organizational climate, and organizational commitment on group cohesion with a cultural difference as an intervening variable. (55), 2013. The Journal of Teaching in Physical Education (JTPE).

Lin, Xiaofang. (, 2017). The influence of paternalistic leadership and transformational leadership on job performance with transformational cognition as a mediating variable. MBA program, Tamkang University.

Lu, Yucun. (, 1999). Study on Leadership Theories. Wenjing, Taipei, Taiwan.

Tan, Jiayu. Translated. (, 1992). On Leadership (John W. Gardner). Bookzone, Taipei.

Wu, Huiqing. (, 2002). An empirical study of player perception, coach leadership behavior, group conflict, group cohesion, and satisfaction. Unpublished master's thesis. Graduate Institute of Physical Education, NTNU.

Yen, Mingzhe \& Chang Jiachang. (, 2006). An Investigation of the cohesion of sports teams. Pp. 114-120. Journal of Physical Education, Changhua Normal University.

$\mathrm{Lu},(2010)$.Attitudes towards aning and older people's intentions to continue working:A Taiwanese study. Career Development International,17(1),83-98.

Lewis, K. (2003).Measuring transactive memory systems in the field: Scale development and

Validation.Journal of Applied Psychology,88(4),587-604 